\title{
Ultra Wideband Coplanar Waveguide Antenna with an Improved Gain using a Frequency Selective Surfaces (FSS)
}

\author{
Komalpreet Kaur, Amanpreet Kaur
}

\begin{abstract}
In this article, an ultra-wideband FSS reflector has been proposed to enhance the gain of a CPW antenna for $U W B$ applications. A CPW fed antenna having dimensions of $38 \mathrm{~mm} \times 38 \mathrm{~mm} \times 1.605 \mathrm{~mm}$ and FSS unit cell having dimensions $14 \mathrm{~mm} \times 14 \mathrm{~mm} \times 1.605 \mathrm{~mm}$ are presented in the paper. $A$ rectangular slot and stubs are interleaved at the outer edges of the patch for achieving desired characteristics of an ultra-wideband for the frequency range of $3.39 \mathrm{GHz}$ to $12.9 \mathrm{GHz}$. Simulation results carried out using the CST microwave 2016 version in the time domain are presented for the proposed antenna. An FSS unit cell designed and simulated using periodic boundary conditions and floquet ports is presented. The combined setup of an array of FSS reflector behind the antenna has been simulated in the time domain. This set up shows an improved performance in terms of antenna's gain. A maximum and minimum gain of $8.14 \mathrm{~dB}$ and $4.98 \mathrm{~dB}$ has been observed with the presence of FSS reflector behind the coplanar waveguide antenna. A significant improvement of $2.9 \mathrm{~dB}$ has been observed over the entire band of antenna's operation.
\end{abstract}

Index Terms: Frequency selective surface (FSS), reflector, reflection parameters, and transmission parameters, gain.

\section{INTRODUCTION}

Nowadays, there is a huge demand for high gain antennas for high frequency and high-speed data communications with low power consumption and interference mitigation [1]. The CPW fed Ultra wideband antennas are characterized by high power handling, high design flexibility, small size, good return loss but along with these advantages it has a problem of low gain [2]. There are many well-known techniques to improve the gain of antennas such as increase the effective length of the antenna [3]; by cutting slots [4] in the substrate or by employing multilayer dielectric substrates [5] and antennas can also be arranged in an array [6]. To improve the gain; a reflector can be used behind any antenna to reflect the electromagnetic waves towards a major lobe of operation. In this technique, the EM rays after striking the reflector form a unidirectional beam, hence increasing the gain of antenna effectively. For this article, we are proposing the technique of placing reflector behind an antenna at a suitable distance to improve its gain. The array of FSS unit cell elements can work as a reflector if its stop band is the resonance band of the antenna. Frequency selective surfaces (FSSs) are basically

\section{Revised Manuscript Received on July 12, 2019.}

Komalpreet Kaur, M.E(ECE) student at Thapar Institute of engineering and technology, Patiala, India

Dr. Amanpreet Kaur, Assistant professor at Thapar Institute of engineering and technology, Patiala, India arrays of conducting patches or apertures on a substrate that act as band reject or band pass filters, respectively, for incoming electromagnetic waves[7-8]. Arrays of the FSS control the propagation of electromagnetic energy and therefore, they can be employed in reflectors [9], frequency scanned antennas, microwave absorbers [10] and recently in applications related with safety and efficiency of the wireless network communications [7-11]. The performance of the FSS depends upon the geometries of the elements used in their design. Predominantly, frequency selective surfaces are used to control the transmission and reflection properties of the incident plane waves [12-13].In this article, FSS surfaces are introduced as a reflector with a CPW fed UWB antenna to improve its gin in order for the antenna to be applicable for high range applications.

\section{DESIGN FOR PROPOSED ANTENNA}

In this article, the proposed antenna with dimension $(\mathrm{L} \times \mathrm{W} \times$ t) $38 \mathrm{~mm} \times 38 \mathrm{~mm} \times 1.605 \mathrm{~mm}$ is presented where $\mathrm{t}$ is the thickness of the antenna. As the antenna is co-planar so its radiation patch, ground, feed line all are printed on the same dielectric substrate of FR-4 material. The dielectric constant 4.4 and the thickness of the substrate is $1.57 \mathrm{~mm}$. Coplanar waveguide antenna having superiority of small size and easy integration. In this article, we use a slotted rectangle with stubs for the antenna geometry. Two stubs each of dimensions $\left(l_{s} \times w_{s} \times t 17 \mathrm{~mm} \times 2.25 \mathrm{~mm} \times 0.035 \mathrm{~mm}\right)$ are interleaved at the outer edges of the rectangle for achieving ultra-wideband characteristics and a slot ( $a \times b)$ of $6 \mathrm{~mm} \times 8 \mathrm{~mm}$ has been cut from the rectangular patch for partially enhancing the bandwidth. The radiating rectangular patch of antenna has dimensions of (11×w1) of $12.25 \mathrm{~mm} \times 16 \mathrm{~mm}$ depicted in figure 1 . Two inverted right angle triangles each of the base $3 \mathrm{~mm}$ and perpendicular length of $1 \mathrm{~mm}$ have been added to the lower part of the slotted rectangle for achieving impedance matching and Ultra wideband characteristics. The reduced ground layer of dimension $\left(l_{g} \times w_{g}\right) 14.5 \mathrm{~mm} \times$ $12 \mathrm{~mm} \times 0.035 \mathrm{~mm}$ is made on both sides of the coplanar feed line for better impedance matching and bandwidth improvement. Coplanar feed line of length $15 \mathrm{~mm}$ and width ( $w_{f}$ ) $4 \mathrm{~mm}$ has been optimized using a parametric sweep option in CST microwave studio 2016. A 
difference of $0.5 \mathrm{~mm}$ is maintained between the reduced ground and feed line which is optimized for obtaining strong coupling.



Fig. 1 front view of the coplanar waveguide antenna

\section{FSS DESIGN}

Proposed Ultra wideband FSS is a 2D array of periodic distribution of Unit cell elements that printed on the dielectric substrate (FR4). This FSS structure is working as a reflector that reflects the incoming electromagnetic waves and forms a unidirectional beam. The dimensions of proposed FSS unit cell and FSS sheet are $14 \mathrm{~mm} \times 14 \mathrm{~mm} \times 1.605 \mathrm{~mm}$ and 42 $\mathrm{mm} \times 42 \mathrm{~mm} \times 1.605 \mathrm{~mm}$ respectively. Figure 2 depicts the iteration wise geometry of the flower shaped unit cell. A flower shaped patch is printed on FR-4 substrate with relative permittivity of 4.4 , loss tangent of 0.24 and thickness substrate is $1.57 \mathrm{~mm}$. Here, it is important to note that thickness of substrate is $1.57 \mathrm{~mm}$ while overall thickness of CPW antenna and Unit cell structure of FSS is $1.605 \mathrm{~mm}$. Moreover, five square slots each of dimension $4 \mathrm{~mm} \times 4 \mathrm{~mm}$ are etched from the copper sheet $(12 \mathrm{~mm} \times 12 \mathrm{~mm} \times 0.035 \mathrm{~mm})$ that is printed on the dielectric substrate to obtain the required Unit cell structure of FSS as depicted in figure 2. Further for the second iteration two stubs of L2/9 interleaved at the adjacent sides of each four slots of the FSS unit cell structure. Here L1 and W1 are the length and width of the unit cell elements. Periodicity of the unit cell $\mathrm{P}=\mathrm{L} 1=\mathrm{W} 1=14 \mathrm{~mm}$.

\section{SIMULATED RESULTS AND DISCUSSION}

Proposed antenna and Frequency selective surfaces (FSS) both are designed and simulated in CST MWS version 2016 using time domain solver and frequency domain solver respectively. The simulation of an antenna with FSS reflector has been done in time domain solver and comparing the simulated results of the reflection coefficient of CPW antenna and antenna gain bandwidth in the absence of FSS and in the presence of FSS. Different development steps and their simulated reflection coefficients have been shown in figure 3 . From here we found an optimized reflection coefficient for the antenna which resonates at $5.52 \mathrm{GHz}$ and $8.91 \mathrm{GHz}$ with return loss $33.93 \mathrm{~dB}$ and $27.94 \mathrm{~dB}$ respectively and covering the frequency range from $3.39 \mathrm{GHz}$ to $12.89 \mathrm{GHz}$ with impedance bandwidth of $9.5 \mathrm{GHz}$.
L1

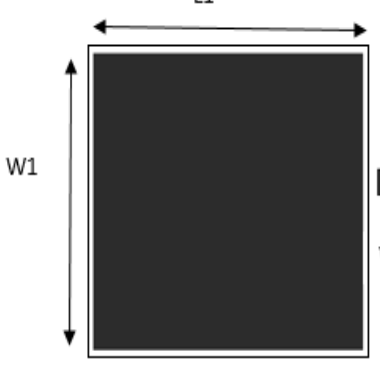

a) 1st stage $L 2 / 9$

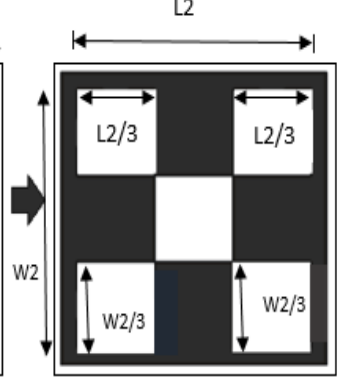

$L 2 / 9$

b) 2nd stage

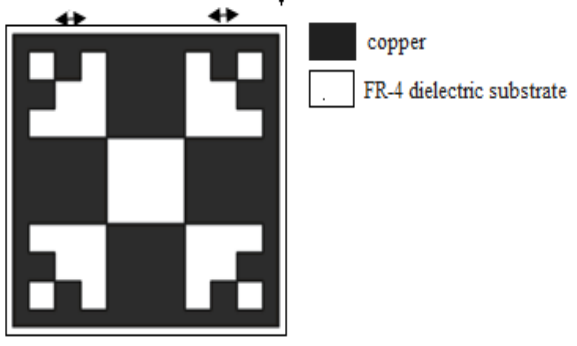

c) Final FSS unit cell

Fig 2 Stepwise geometry of FSS unit cell

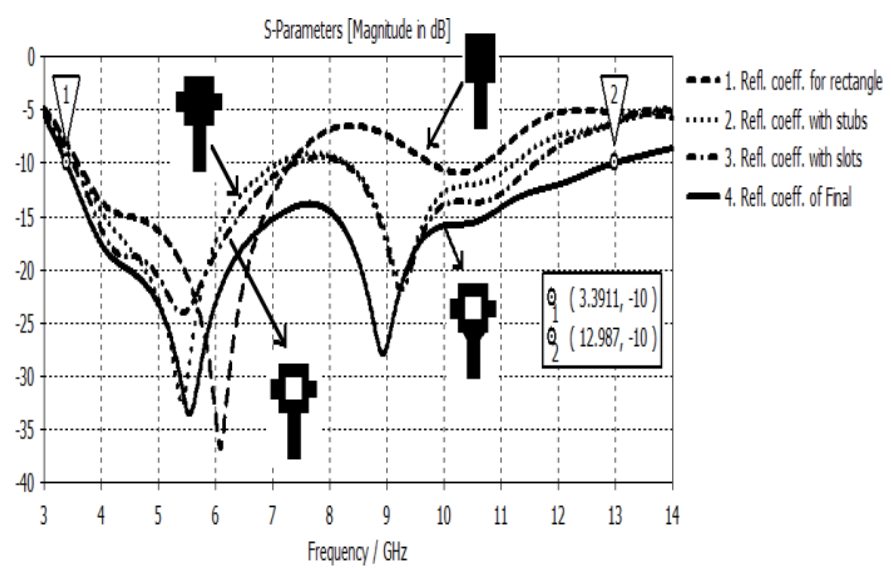

Fig 3 reflection coefficients for Co planer waveguide antenna

Similarly, transmission coefficients for the first iteration of the proposed FSS unit cell depict that it has achieved an ultrawide wide stop band of the frequency range of $3.45 \mathrm{GHz}$ to $11.82 \mathrm{GHz}$.For further enhancement in the bandwidth of the FSS one more iteration has been done and its transmission coefficients, now cover a frequency band from $3.48 \mathrm{GHz}$ to $12.31 \mathrm{GHz}$ as shown in figure 4 . Hence with $2^{\text {nd }}$ iteration there is overall approximate enhancement in bandwidth by $5 \%$.

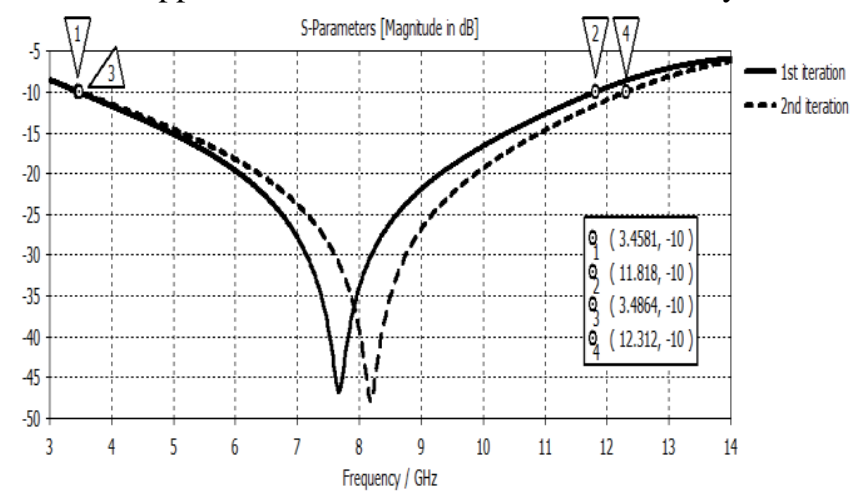

Fig 4 transmission coefficients for FSS unit cell for $1^{\text {st }}$ and $2^{\text {nd }}$ iteration 
Fig 5 depicts the VSWR of the antenna at different frequency ranges.As for the required band, the VSWR value is less than 2 hence the proposed antenna having proper impedance matching between the feed line and antenna.

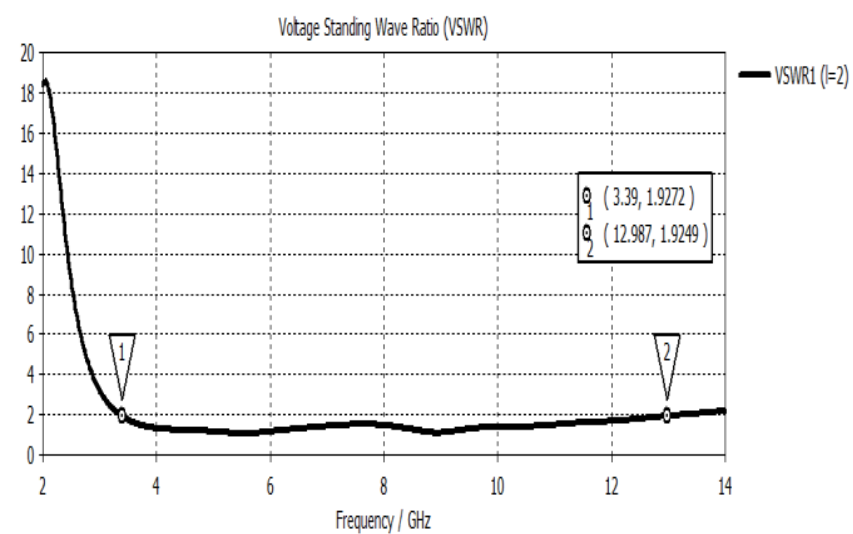

Fig 5 VSWR of proposed antenna V/s frequency

\section{PARAMETRIC STUDY}

The parametric study of the CPW antenna has been mentioned in this section. Figure 6 depicts the effects of the width of reduced ground on the bandwidth of the antenna. As from figure it is verified that as there is increase in the width of the ground, simultaneously reduction in the bandwidth of the antenna takes place. Optimized width of antenna $w_{g}=12$ $\mathrm{mm}$ is selected. At this width proposed antenna demonstrates UWB characteristics.

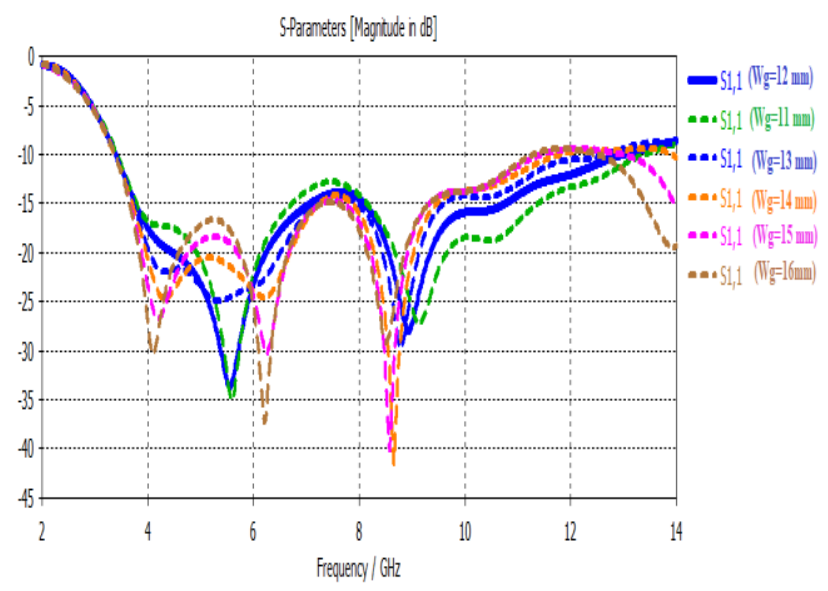

Fig 6 Variation in the width of the ground

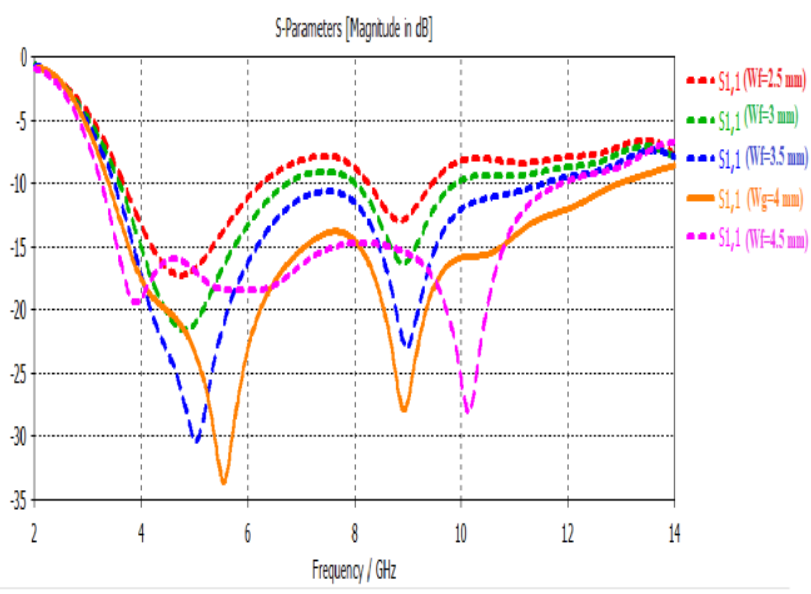

Fig 7 Variation in the width of the feed line
Similarly, variation in the width of the feed line has been shown in figure 7 . It is verified from the simulated results that at different width of the feed line there is variation in bandwidth as well as impedance matching.For thinner feed line $\left(w_{f}=2.5 \mathrm{~mm}\right)$ impedance matching is very poor and the improvement in the impedance matching has been observed for thicker feed line $\left(w_{f}=4 \mathrm{~mm}\right)$ as shown in the figure 7 .

\section{COMPARISON OF RESULTS WITH AND WITHOUT FSS}

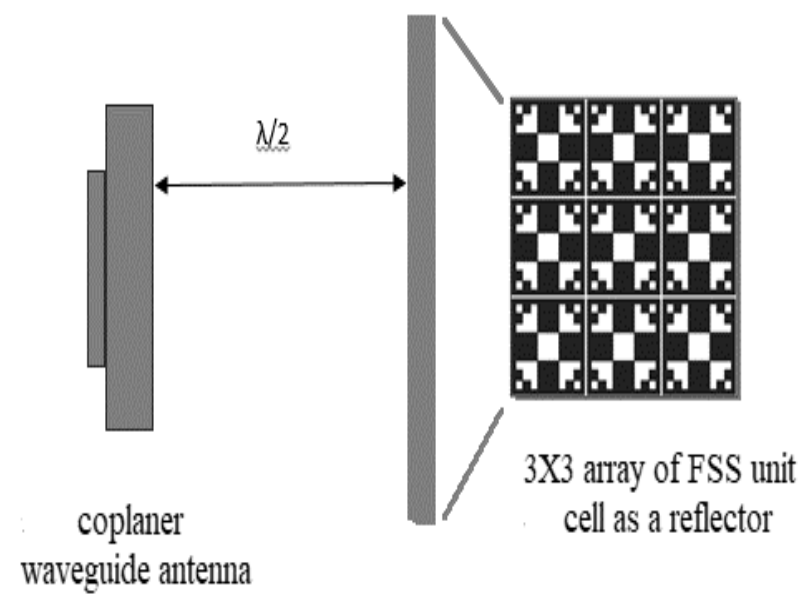

Fig 8 side view of the Set up for antenna and FSS reflector for simulating results

The simulated results for antenna in terms of reflection parameter, Bandwidth and gain have been mentioned in this section. Figure 8 shows that for improving the performance of the antenna in terms of its gain, an array of FSS unit cell elements should be placed behind the antenna at the distance of $\lambda / 2$ where $\lambda$ is the wavelength for centre resonance frequency of the UWB coplanar waveguide antenna, so that electromagnetic wave after striking with a reflector will form unidirectional beam hence improve the gain of the antenna.

Figure 9 depicts the comparison of the simulated results of the reflection coefficient of the CPW antenna with and without FSS reflector. The presence of the array of FSS reflectors behind the coplanar antenna does not affect the transmission coefficients of the antenna much significantly and also maintains the proper impedance match over the entire band. For the frequency of $8.9 \mathrm{GHz}$ the return loss of coplanar antenna in the presence of FSS reflector becomes significantly improved from $-27.9 \mathrm{~dB}$ to $37.3 \mathrm{~dB}$ and it is also observed that enhancement of $1.33 \%$ in the bandwidth of the antenna is there. Figure 11 depicts the comparison of the gain for both cases (presence and absence of FSS reflector). With the use of an array of FSS as a reflector, the gain of the antenna enhances over the entire frequency band from $3.2 \mathrm{GHz}$ to $12.47 \mathrm{GHz}$. The maximum observed gain is 8.14 $\mathrm{dB}$ at a frequency of $12.47 \mathrm{GHz}$ while the minimum gain is $4.98 \mathrm{~dB}$ at a frequency of $3.285 \mathrm{GHz}$ which previously (without FSS reflector) was $1.866 \mathrm{~dB}$. Hence with the presence of FSS reflector, there is an overall enhancement in the gain of the antenna without much significantly affecting its ultra-wideband characteristics. Minimum

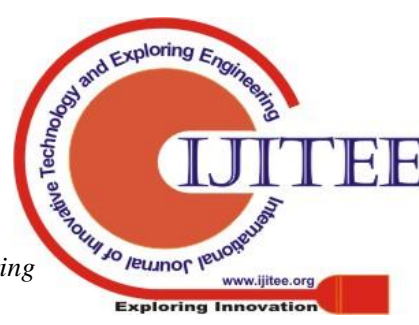


gain enhancement is $0.8 \mathrm{~dB}$ at a frequency of $12.81 \mathrm{GHz}$ while maximum gain enhancement is $3.7 \mathrm{~dB}$ at a frequency of $4.63 \mathrm{GHz}$ and an average gain enhancement for the entire band is $2.25 \mathrm{~dB}$.

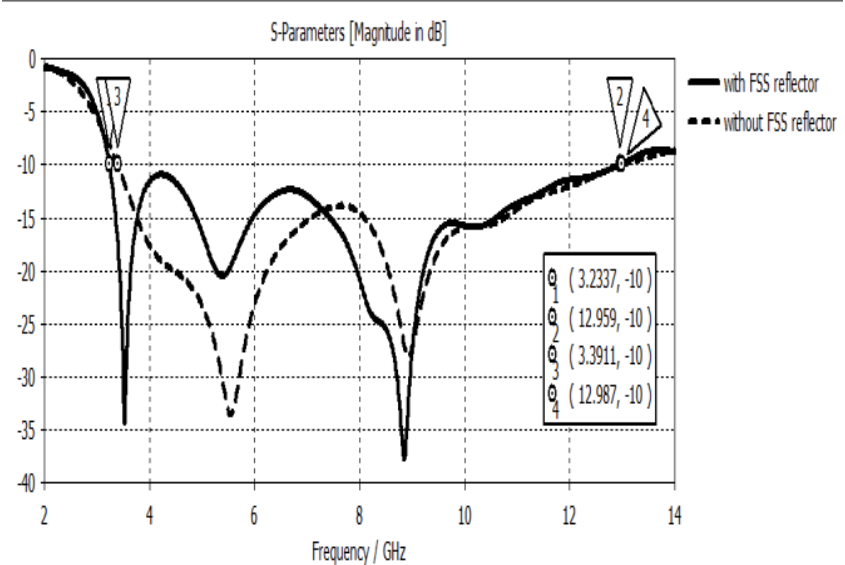

Fig 9 Comparison of reflection coefficients of CPW with and without FSS reflector

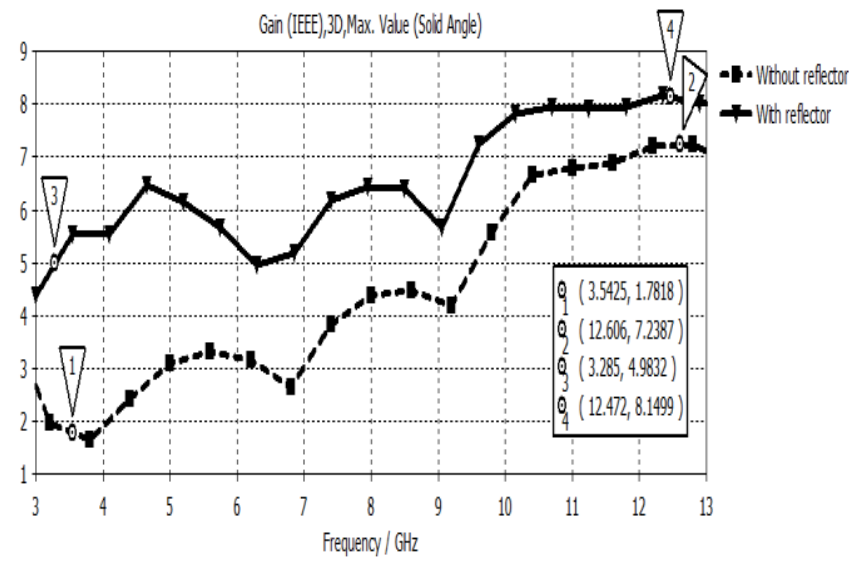

Fig 10 Comparison of gain of CPW antenna with and without FSS reflector

\section{RADIATION PATTEREN OF THE PROPOSED CPW FED ANTENNA WITH AND WITHOUT FSS}
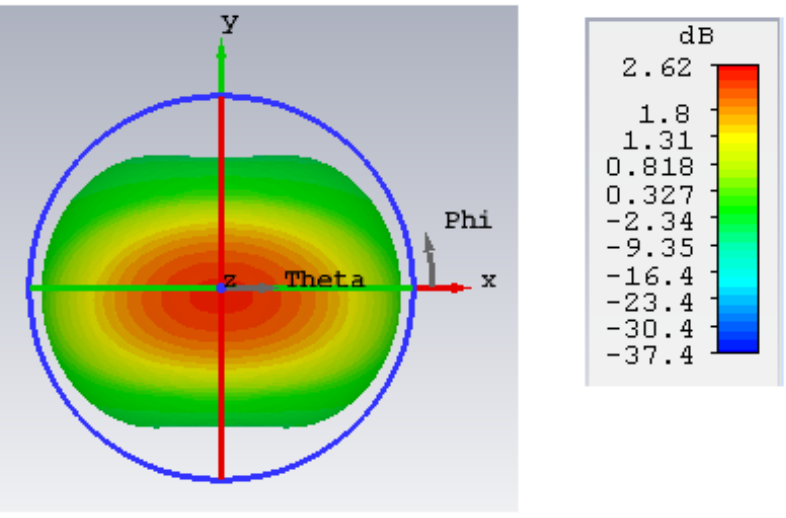

$\begin{array}{ll}\text { Type } & \text { Farfield } \\ \text { Approximation } & \text { enabled }\left(\mathrm{kR}>{ }^{2}\right) \\ \text { Monitor } & \text { farfield }(\mathrm{f}=4.5)[1] \\ \text { Component } & \text { Abs } \\ \text { Output } & \text { Gain } \\ \text { Frequency } & 4.5 \\ \text { Rad. effic. } & -0.4599 \mathrm{~dB} \\ \text { Tot. effic. } & -0.5023 \mathrm{~dB} \\ \text { Gain } & 2.618 \mathrm{~dB}\end{array}$

(a)
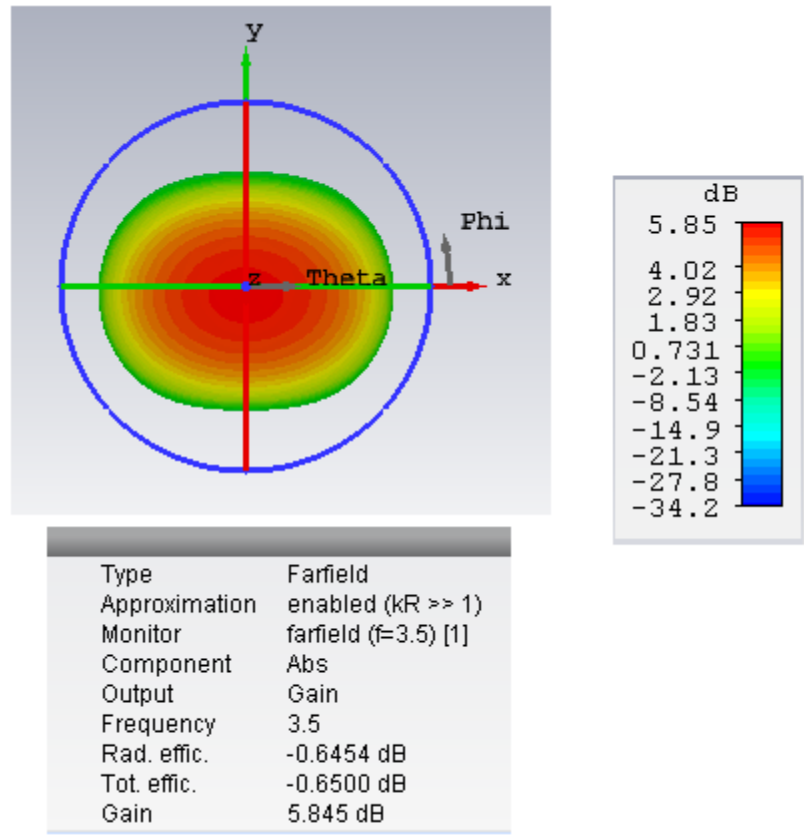

(b)

Fig 11(a-b) Radiation pattern of CPW antenna with and without FSS reflector respectively

Figure 11 (a) depicts the 3D radiation pattern of a CPW fed antenna without a use of FSS reflector. A single CPW antenna without FSS reflector having gain of $2.618 \mathrm{~dB}$ at frequency of $3.5 \mathrm{GHz}$ is seen. In the presence of FSS reflector side lobes and back lobes merge into main lobe and hence an enhancement in the gain of antenna to $5.845 \mathrm{~dB}$ is seen as shown in fig 11(b).

\section{CONCLUSION}

From the simulated reflection coefficients of coplanar waveguide antenna with and without FSS reflector, it is verified that the presence of reflector behind the coplanar waveguide antenna does not significantly affect the Ultra wideband characteristics, return loss of the antenna. In fact, the presence of FSS reflector enhances the gain and radiation bandwidth of the antenna. An overall enhancement of antenna average gain of $2.9 \mathrm{~dB}$ for gathering the entire UWB allows the antenna to be used for long-range UWB applications.

\section{ACKNOWLEDGMENT}

The authors are thankful to the entire staff and faculty of electronics and communication department, Thapar Institute of Engineering and Technology, Patiala for giving us this opportunity and support through this research.

\section{REFERENCES}

[1]Ekta Saini, Richa Bhatia, Saurabh Prakash, "High-speed broadband communication system for moving trains using Free Space Optics", 2016 International Conference on Computational Techniques in Information and Communication Technologies (ICT ICT),pp.1-4.

[2]Mahdi Ghorbani and Habib Ghorbaninejad,2017 "Design Of A High Gain Bandwidth Improved Aperture Antenna Using A Frequency Selective Surface", ACES Journal, Vol. 32, No.4

[3] Valentino Trainotti, Gonzalo Figueroa 2010, "Vertically Polarized Dipoles and Monopoles, Directivity, 
Effective Height and Antenna Factor", IEEE Transactions on broadcasting, VOL. 56, NO. 3.

[4]M. T. Islam, M. N. Shakib, and N. Misran, 2009 "Multi-Slotted Microstrip Patch Antenna for Wireless Communication", Progress in Electromagnetics Research Letters, Vol. 10, pp.11-18.

[5]Giorgio Montisci, Zusheng Jin, Mingchao Li, Hu Yang, Giovanni Andrea Casula, Giuseppe Mazzarella, and Alessandro Fanti, 2013"Design of Multilayer Dielectric Cover to Enhance Gain and Efficiency of Slot Arrays", International Journal of Antennas and Propagation, pp.1-6

[6]C. A. Balanis. Antenna Theory2015: Analysis and Design, Third Edition: John Wiley \& Sons.

[7]T.K. Wu,1995 Frequency selective surfaces and grid array, Wiley, New York

[8]B.A. Munk, 2000 Frequency selective surface - theory and design, Wiley, New York, .

[9]Y. Ranga, K. P. Esselle, L. Matekovits3, and S. G. Hay,2012 "Increasing the Gain of a Semicircular Slot UWB Antenna Using an FSS Reflector", IEEE, pp.478-481.

[10] Silva MWB, Araujo HX, Campos ALPS, 2018 "Design of a narrow band and wideband absorbers using resistive FSS concept for the $X$ and $\mathrm{Ku}$ band application", Microwave Optical Technology Letters, vol.60, pp.2128-2132.

[11] A.G. D'Assunc,ão, Jr.2012, Analysis of integrated circuits and FSS using WCIP for applications at microwaves and terahertz bands (in Portuguese), Ph.D. Dissertation, Federal University of Campina Grande, PB, Brazil.

[12] Silva MR, N_obrega CL, Silva PHF, D'assunção AG.2013 , "Stable and compact multiband frequency selective surfaces with fractal configurations", IET Microwave Antennas Propagation, pp.543-551.

[13] Sanz-Izquierdo B, Parker EA.,2014 "Dual polarized reconfigurable frequency selective surfaces", IEEE Trans Antennas Propagation, pp.764-771

\section{AUTHORS PROFILE}

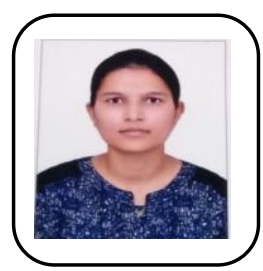

Komalpreet Kaur received a B.tech degree in Electronics and communication from university college of engineering (UCoE), Punjabi University,Patiala. She is perusing her M.E degree from the Thapar Institute of Engineering and technology, Patiala. Her work includes planer antenna and frequency selective surfaces.



Dr. Amanpreet Kaur received in 2004 B.E. (ELECTRONICS \& COMMUNICATIONS) From Jammu University, Jammu. She did M. E. (specialization in Wireless Communication) and Ph.D. (Micro strip antennas for Wireless Communication) from Thapar Institute of Engineering \& Technology, Patiala in 2006 and 2016 respectively. Presently working as Assistan Professor in the Department of Electronics and Communication Engineering at Thapar Institute of Engineering \& Technology Patiala (Punjab) full time, teaching B.E. and M.E. students since July 2006 till date. She is an active member of the editorial team of "International Journal of Core Research in Communication Engineering", STM journals Journal of Microwave Engineering \& Technologies (JoMET), Journal of Telecommunication, Switching Systems, and Networks (JoTSSN). Her research interests include design and modeling of antennas, Array and FSS. 